\title{
In Vitro Preliminary Evaluation of Bacterial Attachment on Grooved and Smooth Healing Abutments
}

\author{
Ofer Moses ${ }^{1}$, Carlos E. Nemcovsky ${ }^{1}$, Israel Lewinstein ${ }^{2}$, Hasan Zoabi ${ }^{3}$, Miron Weinreb ${ }^{3}$ (D), \\ Shifra Levartovsky ${ }^{2, *,+}$ (D) and Shlomo Matalon ${ }^{2,+}$ \\ 1 Department of Periodontology and Dental Implantology, School of Dental Medicine, Tel Aviv University, \\ Tel Aviv 6997801, Israel; mosesofer@gmail.com (O.M.); carlos@tauex.tau.ac.il (C.E.N.) \\ 2 Department of Oral Rehabilitation, School of Dental Medicine, Tel Aviv University, Tel Aviv 6997801, Israel; \\ Lewinsdr@gmail.com (I.L.); matalons@tauex.tau.ac.il (S.M.) \\ 3 Department of Oral Biology, School of Dental Medicine, Tel Aviv University, Tel Aviv 6997801, Israel; \\ Hasanzoabi@gmail.com (H.Z.); Weinreb@tauex.tau.ac.il (M.W.) \\ * Correspondence: shifra@tauex.tau.ac.il \\ + These authors contributed equally to this article.
}

Received: 15 May 2020; Accepted: 24 June 2020; Published: 27 June 2020

\begin{abstract}
This in vitro preliminary study investigated the attachment of Fusobacterium nucleatum and Porphyromonas gingivalis on titanium alloy healing abutments, which differed in their surface macro-morphology: one was groove-marked while the other was completely smooth. Altogether, twenty implant-healing abutments, ten of each macro-morphology, were evaluated with a single type of bacterial strain. Accordingly, four groups of five abutments each were created. The sterilized healing abutments with the cultured bacteria were placed under anaerobic conditions for $48 \mathrm{~h}$ at $37^{\circ} \mathrm{C}$. Afterwards, the abutments were examined with a scanning electron microscope, at a $2500 \mathrm{x}$ magnification. Attached bacteria were quantified in the four vertical quarters within the grooved abutments and in the two most coronal millimeters of the smooth abutments. The results were analyzed by applying two-way ANOVA, with square root transformation for a normal distribution. The bacterial attachment of both strains was statistically significantly larger in the grooved abutment areas than on the smooth surfaces ( $p \leq 0.0001)$, twenty times so for Porphyromonas gingivalis and a hundred times so for Fusobacterium nucleatum.
\end{abstract}

Keywords: smooth healing abutment; grooved healing abutment; bacterial growth; SEM

\section{Introduction}

Healing abutments may be placed on dental implants either following implant placement or in two-stage surgical protocols, at the time of their exposure to the oral environment. Differing from dental implants, where micro- and macro-grooving has been shown to enhance soft and hard tissue integration [1], the coronal portion of healing abutments is exposed to the oral cavity and, therefore, subject to bacterial colonization [2]. Abutments' surface characteristics and the implant-abutment interface significantly affect supragingival and subgingival biofilm accumulation. An increased surface roughness facilitates biofilm formation [3], which, in turn, affects the peri-implant soft tissues [3-5]. Healing abutments are placed in a surgical wound area. Enhanced bacterial plaque accumulation leads to peri-implant soft tissue inflammation, which, in turn, affects soft and hard tissue integration to the dental implant, especially in the crestal area [6-8]. Bacterial adhesion and proliferation lead to an organized biofilm [9]; hence, rough surfaces accumulate up to twenty-five times more sub-gingival plaque than smoother ones, also leading to more difficult removal [10-12].

The consequences of enhanced plaque build-up on healing abutments are not clear; however, it is evident that bacterial accumulation, especially in a surgical wound healing area, around implants 
enhances inflammatory reactions in the surrounding gingiva and alveolar mucosa as well as around teeth [13].

Inflammatory mediators are enhanced in inflamed tissues, thus promoting angiogenesis [14] and pro-inflammatory cytokines [15]. Therefore, this inflammatory process within the soft tissue around healing abutments is also likely to affect implant osseous integration.

Fusobacterium nucleatum and Porphyromonas gingivalis are well known perio-pathogenic bacteria. Fusobacterium nucleatum belongs to the Bacteroidaceae family. It is a Gram-negative anaerobic species of the phylum Fusobacteria, numerically dominant in dental plaque biofilms, and important in biofilm ecology and human infectious diseases [16]. Porphyromonas gingivalis is a Gram-negative anaerobic bacterium [17]. Infection by Porphyromonas gingivalis could modulate host immune responses and ultimately destroy the balance between the normal cell cycle and apoptosis, thereby leading to periodontal tissue destruction [18,19].

Most healing abutments are made of titanium alloys [20]. However, the influence that certain alterations, such as laser markings or the machining of depth grooves on the abutment surface, may have on bacterial adhesion has not been evaluated.

This preliminary in vitro study aimed to evaluate the bacterial attachment of two strains onto titanium alloy healing abutments, from the same manufacturer, differing only in their surface macro-morphology; while one was CNC (Computer Numerical Control) machine-grooved, the other was completely smooth.

\section{Methods}

\subsection{Tested Materials}

Two equal groups of ten titanium grade- $\mathrm{V}, 5 \mathrm{~mm}$-height and $3.85 \mathrm{~mm}$-diameter implant-healing abutments (AlphaBio Tec Ltd., Petach Tikva, Israel), were evaluated:

Group I: 10 smooth healing abutments with a machined smooth surface (Figure 1); Group II: 10 healing abutments with a marked (grooved) surface roughness value (Ra) of $0.8 \mu \mathrm{m}$ (Figure 2).

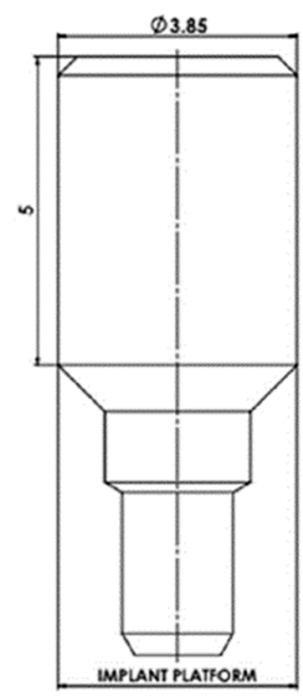

Figure 1. Machined smooth surface. 


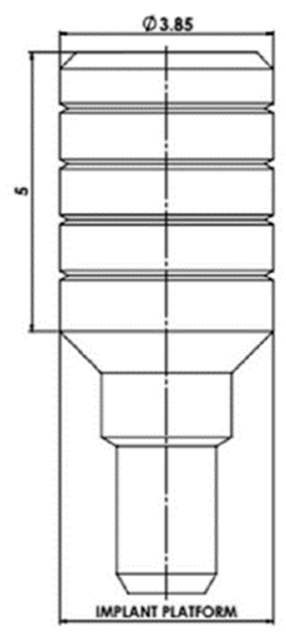

Figure 2. Marked (grooved) surface.

\subsection{Tested Bacteria and Culturing Conditions}

The cultured bacterial strains were Fusobacterium nucleatum (ATCC 1594) (F.n) from frozen stock cultures grown anaerobically in Sherdler broth (Becton, Dickinson and Company, Franklin Lakes, NJ, USA) and Porphyromonas gingivalis (ATCC 33279) (P.g) from frozen stock cultures grown anaerobically in Wilkins-Chalgren broth (OXOID Ltd., Basingstoke, Hampshire, UK). Each of these strains was cultured on five smooth-surfaced and five grooved healing abutments, thus yielding four experimental groups.

Sterilized abutments were screwed to the inner surface of the microtiter plate cover and immersed in a 96-well microtiter plate (96-well flat-bottom Nunclon, Copenhagen, Denmark), each well containing 250 microliters of growth medium suitable for each bacterial strain (F.n was in Sherdler broth and P.g, in Wilkins-Chalgren broth). Into each well, ten microliters of bacterial suspension (O.D 0.6 at $600 \mathrm{~nm}$ ), representing $1 \times 10^{6}$ cells $/ \mathrm{mL}$, were added, and the plates were incubated under anaerobic conditions for $48 \mathrm{~h}$ at $37^{\circ} \mathrm{C}$ and vortexed automatically for five seconds every $30 \mathrm{~min}$ (VesaMax, Molecular Device Corporation, San Jose, CA, USA) in order to guarantee the homogeneity of the bacterial suspension. After $48 \mathrm{~h}$ (early colonization), the abutments were removed from the plate. Close direct contact between the bacteria and the abutment surface and bacterial suspension fluids was accomplished by an evaporation process. The abutments were fixated with $2.5 \%$ glutaraldehyde in PBS and gold-plated for examination with a scanning electron microscope (SEM) (JSM 840A, Jeol Ltd., Tokyo, Japan), at a 2500x magnification and with a 47.9 micrometer horizontal field and accelerating voltage of $25 \mathrm{kV}$.

Bacterial attachment counts were performed on the four vertical quarters of the grooved abutments, both in smooth and grooved areas, while on the smooth abutments, they were performed in the two coronal millimeters (surface area of $958 \mu \mathrm{m}^{2}$ for each quarter) using the Image J 1.4 software (NIH, Bethesda, MD, USA).

\subsection{Statistical Analysis}

Statistical analysis consisted of two-way ANOVA after square root transformation was applied for a normal distribution. A $p$ value $\leq 0.05$ was considered statistically significant.

\section{Results}

The results of the bacterial counts are presented in Table 1 and Figure 3a,b. (1) Similar bacterial counts for both strains were found on the smooth areas between the grooves of the marked healing abutments and on the smooth healing abutments. (2) Bacterial adherence was different for each strain, and F.n attachment to all surfaces was considerably larger than that of P.g. (3) The most important finding was that the total bacterial counts for both strains in the grooved areas were significantly higher 
( $p \leq 0.0001)$ than those in the smooth areas. The mean P.g counts were $\sim 20$ times larger and those of F.n were over 100 times larger in the grooves compared to on the smooth surfaces.

Table 1. Bacterial counts (mean and SD) in the four experimental groups.

\begin{tabular}{lcccccc}
\hline \multirow{2}{*}{ Abutment Type } & \multicolumn{2}{c}{ F.n Counts (CFU) } & \multicolumn{2}{c}{ P.g Counts (CFU) } \\
\cline { 3 - 6 } & & \multicolumn{4}{c}{ Bacteria/Field } \\
\cline { 2 - 6 } & & Mean & SD & Mean & SD \\
\hline \multirow{3}{*}{ Abutment Type } & \multicolumn{2}{c}{ Smooth } & 10.1500 & 3.33791 & 192.1750 & 66.70708 \\
\cline { 2 - 6 } & \multirow{2}{*}{ Grooved } & Within grooves & 1043.5500 & 397.52536 & 4026.3000 & 347.55053 \\
\cline { 2 - 6 } & & Between grooves & 11.4500 & 4.92133 & 175.7000 & 44.72210 \\
\hline
\end{tabular}

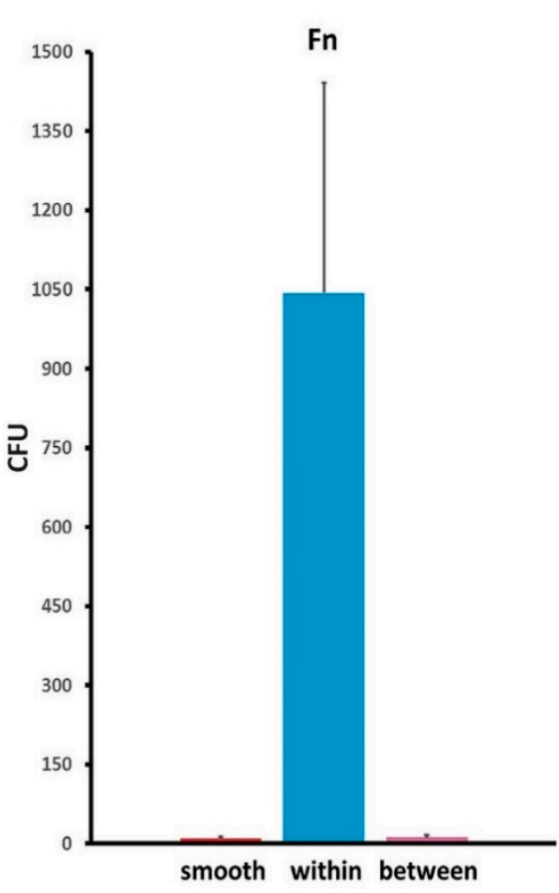

(a)

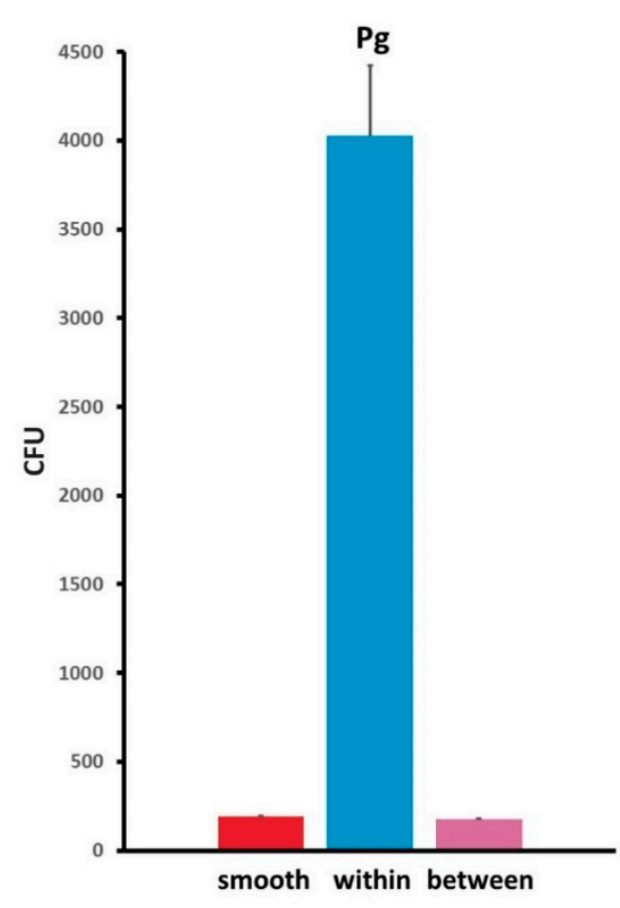

(b)

Figure 3. (a) Fusobacterium nucleatum count on smooth surface, in the grooves and in between; (b) Porphyromonas gingivalis count on smooth surface, in the grooves and in between. CFU (colony-forming unit).

\section{Scanning Electron Microscopy}

Pictures of the grooved and smooth abutment surfaces taken under SEM are shown in Figures 4-7, and a difference in shape between the two bacterial strains may be appreciated. The bacterial adherence of both strains is clearly larger in the grooved areas of the marked abutments as compared to in the smooth ones. 


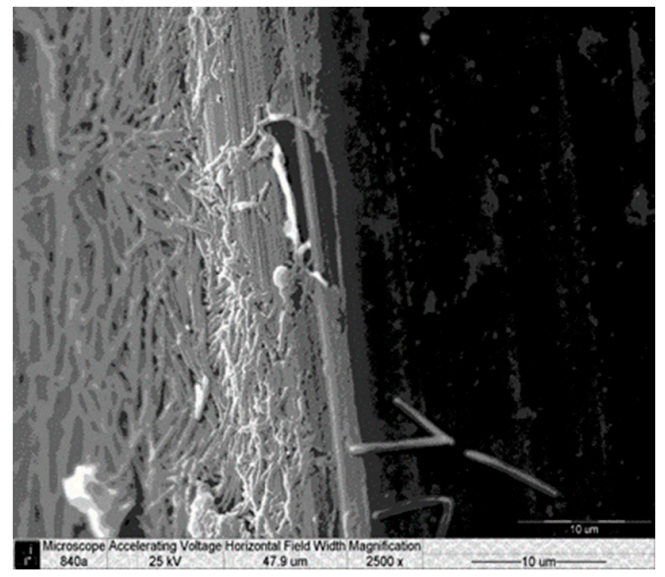

Figure 4. Fusobacterium nucleatum attached on the border-line between the smooth (dark side of the figure) and the grooved parts (bright side, the left side of the figure). The larger number of bacteria within the groove as compared to that in the machined area of the healing cap (right side) is evident (magnification, $\times 2500$ ).

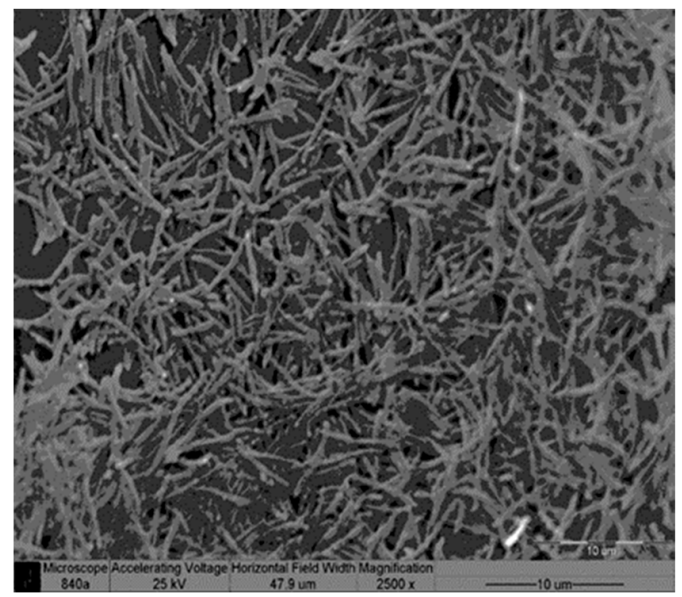

Figure 5. High number of Fusobacterium nucleatum found within the grooved part of the healing cap (magnification, $\times 2500$ ).

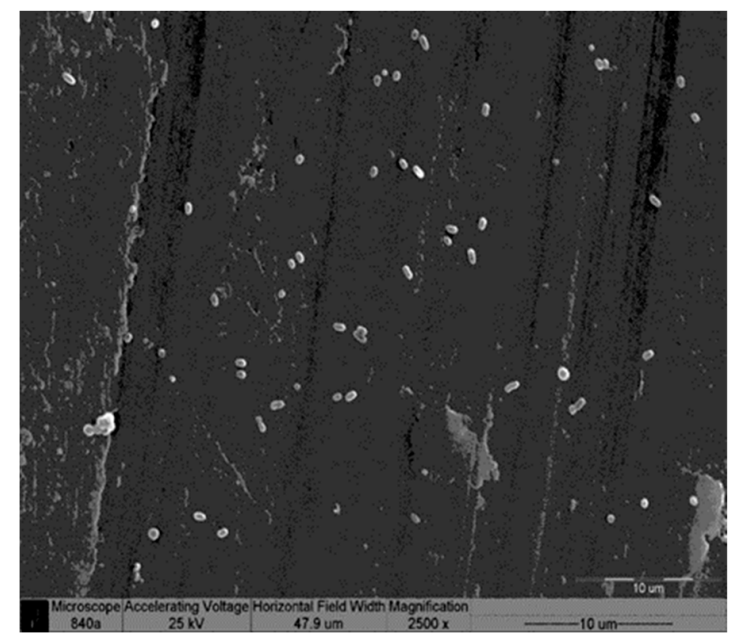

Figure 6. Porphyromonas gingivalis growth on the machined surface. Note the low bacterial count in this area (magnification, $\times 2500$ ). 


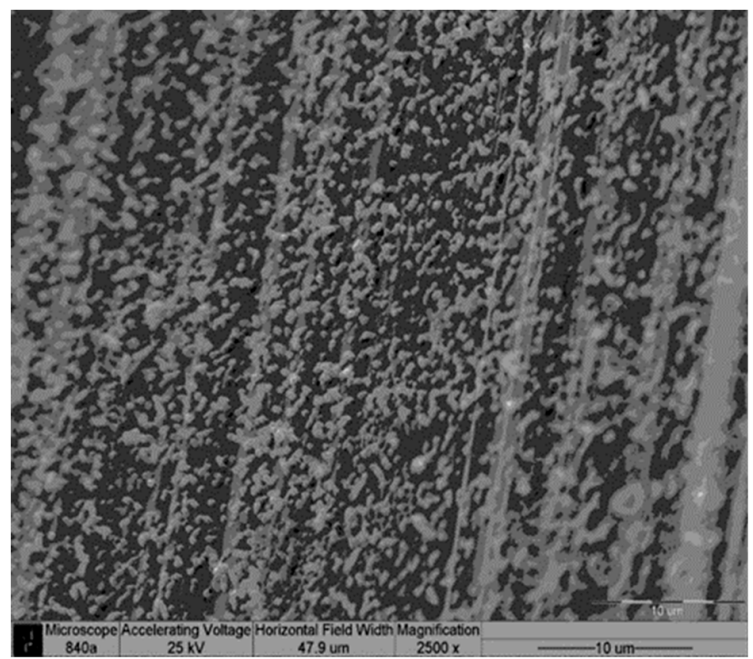

Figure 7. Porphyromonas gingivalis growth on the inner aspect of the grooved surface. Note the high bacterial count in this area (magnification, $\times 2500$ ).

\section{Discussion}

The effect of depth grooves on healing abutments on bacterial adhesion has hardly been evaluated; the present in vitro study reveals, for the first time, their negative effect, by significantly enhancing bacterial adhesion. Previous reports have shown that surface modifications on dental implants and abutments play a relevant role in bacterial adhesion [3]. The chemical and physical surface characteristics of trans-gingival implant components significantly influence bacterial attachment. The control of bacterial infection in the peri-implant soft and hard tissues is critical for the long-term stability of implants supporting oral rehabilitation $[4,10,21,22]$. There are no previous reports concerning the relationship of the healing abutment macro-morphology (machined or grooved), used in dental implant procedures, to clinical and microbiological parameters; however, it is clear that bacterial plaque negatively affects peri-implant tissue stability [22].

Our results demonstrate the significantly larger bacterial attachment of both strains in the grooved areas compared to in the smooth areas of the healing abutments, especially of F.n, which was 100 times larger. Our results are in accordance with those of Bermejo et al. that showed the significant accumulation of pathogenic bacteria (F.nucleatum and A. actinomycetemcomitans) on moderate-roughness compared to minimal-roughness implant surfaces [23].

Peri-implantitis presents a heterogeneous microbiota, where perio-pathogenic bacteria such as Porphyromonas gingivalis and Prevotella intermedius/nigrescens together with asaccharolytic anaerobic Gram-positive rods and other Gram-negative rods may be found [24]. The treatment of peri-implantitis is mainly based on different mechanical and physical means to remove biofilms from the implant surface [25].

Healing abutments are usually placed following a surgical intervention, such as implant placement or uncovering. In a recent randomized, controlled study, either micro-grooved or machined healing abutments were placed. After nonsurgical treatment and the reconstitution of oral hygiene measures, the incidence of peri-implant mucositis was found to be significantly lower at the non-grooved abutments [26].

Bacterial colonization, as found in this in vitro study, was enhanced in grooved healing caps. Bacterial accumulation following implant uncovering might induce pro-inflammatory events in the mucosa, jeopardizing optimal healing. Epithelial cell attachment may prevent the bacterial invasion of titanium surfaces; however, early bacterial colonization on these surfaces may, in turn, downregulate this effect. Peri-implant soft tissue clinical maturity is apparently established as early as four weeks 
following implant placement in a one-stage surgical protocol, while the newly created peri-implant crevices are colonized by bacteria within two weeks [27].

Soft tissue healing and maturation around dental implants placed in a one-stage protocol may be at greater risk, since bacterial plaque can cause inflammation, which negatively affects osseointegration.

In the present study, only two types of bacterial lines with known morphology were tested to avoid result masking from full plaque presenting wide morphologic variations. Since bacteria are present within the implant-abutment connection, one-stage dental implants become contaminated even during the first two postoperative weeks. These microorganisms can penetrate the sulcus around the fixtures and disrupt healing and osseointegration [28-30]. Using machined smooth abutments, as was demonstrated in the current study, may minimize bacterial adherence, which impairs osseointegration, especially in one-stage dental implants.

The limitations of the present preliminary in vitro investigation are the number of samples, the fact that only two types of pathogenic bacteria were evaluated and the specific methodology used to mimic the clinical situation of bacterial adhesion and accumulation.

\section{Conclusions}

In spite of the limitations of this in vitro preliminary study, bacterial adherence was significantly enhanced on grooved healing compared to machined smooth abutments.

The present in vitro study did not evaluate the biological consequences of higher bacterial colonization on these abutments.

Further studies to investigate the different molecular and cellular reactions to different types of healing abutments as well as their clinical relevance are still needed.

Author Contributions: Conceptualization, O.M., C.E.N. and S.M.; Formal analysis, O.M., M.W. and S.M.; Investigation, I.L., H.Z. and S.M.; Methodology, C.E.N., M.W. and S.L.; Writing-original draft, O.M. and C.E.N.; Writing-review \& editing, S.L. and S.M. All authors have read and agreed to the published version of the manuscript.

Funding: This research received no external funding.

Acknowledgments: The authors thank Alpha Bio Tec company, Petach Tikva, Israel, for providing both types of healing caps used in this in-vitro study

Conflicts of Interest: The authors declare no conflict of interest.

\section{Abbreviations}

F.n Fusobacterium nucleatum

P.g Porphyromonas gingivalis

SEM Scanning electron microscope

\section{References}

1. Guarnieri, R.; Di Nardo, D.; Gaimari, G.; Miccoli, G.; Testarelli, L. Short vs. standard laser-Microgrooved implants supporting single and splinted crowns: A prospective study with 3 years follow-up. J. Prosthodont. 2019, 28, e771-e779. [CrossRef] [PubMed]

2. Esposito, M.; Hirsch, J.M.; Lekholm, U.; Thomsen, P. Biological factors contributing to failures of osseointegrated oral implants. (II) Etiopathogenesis. Eur. J. Oral Sci. 1998, 106, 721-764. [CrossRef] [PubMed]

3. Subramani, K.; Jung, R.E.; Molenberg, A.; Hammerle, C.H. Biofilm on dental implants: A review of the literature. Int. J. Oral Maxillofac. Implant. 2009, 24, 616-626.

4. Grössner-Schreiber, B.; Griepentrog, M.; Haustein, I.; Müller, W.D.; Lange, K.P.; Briedigkeit, H.; Göbel, U.B. Plaque formation on surface modified dental implants: An in vitro study. Clin. Oral Implant. Res. 2001, 12, 543-551. [CrossRef] [PubMed] 
5. Elter, C.; Heuer, W.; Demling, A.; Hannig, M.; Heidenblut, T.; Bach, F.W.; Stiesch-Scholz, M. Supra- and subgingival biofilm formation on implant abutments with different surface characteristics. Int. J. Oral Maxillofac. Implant. 2008, 23, 327-334.

6. Rimondini, L.; Farè, S.; Brambilla, E.; Felloni, A.; Consonni, C.; Brossa, F.; Carrassi, A. The effect of surface roughness on early in vivo plaque colonization on titanium. J. Periodontol. 1997, 68, 556-562. [CrossRef]

7. Yoshinari, M.; Oda, Y.; Kato, T.; Okuda, K.; Hirayama, A. Influence of surface modifications to titanium on oral bacterial adhesion in vitro. J. Biomed. Mater. Res. 2000, 52, 388-394. [CrossRef]

8. Yoshinari, M.; Oda, Y.; Kato, T.; Okuda, K. Influence of surface modifications to titanium on antibacterial activity in vitro. Biomaterials 2001, 22, 2043-2048. [CrossRef]

9. Quirynen, M.; Bollen, C.M. The influence of surface roughness and surface-free energy on supra- and subgingival plaque formation in man. A review of the literature. J. Clin. Periodontol. 1995, 22, 1-14. [CrossRef]

10. Quirynen, M.; van der Mei, H.C.; Bollen, C.M.; Schotte, A.; Marechal, M.; Doornbusch, G.I.; Naert, I.; Busscher, H.J.; van Steenberghe, D. An in vivo study of the influence of the surface roughness of implants on the microbiology of supra- and subgingival plaque. J. Dent. Res. 1993, 72, 1304-1309. [CrossRef]

11. Quirynen, M.; Bollen, C.M.; Papaioannou, W.; Van Eldere, J.; van Steenberghe, D. The influence of titanium abutments surface roughness on plaque accumulation and gingivitis: Short-term observations. Int. J. Oral Maxillofac. Implant. 1996, 11, 169-178.

12. Teughels, W.; Van Assche, N.; Sliepen, I.; Quirynen, M. Effect of material characteristics and/or surface topography on biofilm development. Clin. Oral Implant. Res. 2006, 17, 68-81. [CrossRef] [PubMed]

13. Rasperini, G.; Maglione, M.; Cocconcelli, P.; Simion, M. In vivo early plaque formation on pure titanium and ceramic abutments: A comparative microbiological and SEM analysis. Clin. Oral Implant. Res. 1998, 9, 357-364. [CrossRef] [PubMed]

14. Suthin, K.; Matsushita, K.; Machigashira, M.; Tatsuyama, S.; Imamura, T.; Torii, M.; Izumi, Y. Enhanced expression of vascular endothelial growth factor by periodontal pathogens in gingival fibroblasts. J. Periodontal Res. 2003, 38, 90-96. [CrossRef] [PubMed]

15. Jiang, Y.; Mehta, C.K.; Hsu, T.Y.; Alsulaimani, F.F. Bacteria induce osteoclastogenesis via an osteoblast-independent pathway. Infect. Immun. 2002, 70, 3143-3148. [CrossRef] [PubMed]

16. Signat, B.; Roques, C.; Poulet, P.; Duffaut, D. Role of Fusobacteriumnucleatum in periodontal health and disease. Curr. Issues Mol. Biol. 2011, 13, 25-36. [PubMed]

17. Holt, S.C.; Ebersole, J.L. Porphyromonas gingivalis, Treponema denticola, and Tannerella forsythia: the 'red complex', a prototype polybacterial pathogenic consortium in periodontitis. Periodontol. 2000 2005, 38, 72-122. [CrossRef]

18. Yamamoto, T.; Kita, M.; Oseko, F.; Nakamura, T.; Imanishi, J.; Kanamura, N. Cytokine production in human periodontal ligament cells stimulated with Porphyromonas gingivalis. J. Periodontal Res. 2006, 41, 554-559. [CrossRef]

19. Koutouzis, T.; Eastman, C.; Chukkapalli, S.; Larjava, H.; Kesavalu, L. A novel rat model of polymicrobial peri-implantitis: A preliminary study. J. Periodontol. 2017, 88, e32-e41. [CrossRef]

20. Steinberg, D.; Sela, M.N.; Klinger, A.; Kohavi, D. Adhesion of periodontal bacteria to titanium and titanium alloy powders. Clin. Implant. Res. 1998, 9, 67-72. [CrossRef]

21. Bollen, C.M.; Papaioanno, W.; Van Eldere, J.; Schepers, E.; Quirynen, M.; van Steenberghe, D. The influence of abutment surface roughness on plaque accumulation and peri-implant mucositis. Clin. Oral Implant. Res. 1996, 7, 201-211. [CrossRef] [PubMed]

22. Sridhar, S.; Wang, F.; Wilson, T.G., Jr.; Valderrama, P.; Palmer, K.; Rodrigues, D.C. Multifaceted roles of environmental factors toward dental implant performance: Observations from clinical retrievals and in vitro testing. Dent. Mater. 2018, 34, e265-e279. [CrossRef] [PubMed]

23. Bermejo, P.; Sánchez, M.C.; Llama-Palacios, A.; Figuero, E.; Herrera, D.; Sanz Alonso, M. Biofilm formation on dental implants with different surface micro-topography: An in vitro study. Clin. Oral Implant. Res. 2019, 30, 725-734. [CrossRef] [PubMed]

24. Lafaurie, G.I.; Sabogal, M.A.; Castillo, D.M.; Rincón, M.V.; Gómez, L.A.; Lesmes, Y.A.; Chambrone, L. Microbiome and microbial biofilm profiles of peri-implantitis: A systematic review. J. Periodontol. 2017, 88, 1066-1089. [CrossRef] [PubMed] 
25. Lollobrigida, M.; Fortunato, L.; Serafini, G.; Mazzucchi, G.; Bozzuto, G.; Molinari, A.; Serra, E.; Menchini, F.; Vozza, I.; De Biase, A. The prevention of implant surface alterations in the treatment of periimplantitis: Comparison of three different mechanical and physical treatments. Int. J. Environ. Res. Public Health 2020, 17, 2624. [CrossRef] [PubMed]

26. Schwarz, F.; Becker, J.; Civale, S.; Hazar, D.; Iglhaut, T.; Iglhaut, G.J. Onset, progression and resolution of experimental peri-implant mucositis at different abutment surfaces: A randomized controlled two-centre study. Clin. Periodontol. 2018, 45, 471-483. [CrossRef]

27. DeAngelo, S.J.; Kumar, P.S.; Beck, F.M.; Tatakis, D.N.; Leblebicioglu, B. Early soft tissue healing around one-stage dental implants: Clinical and microbiologic parameters. J. Periodontol. 2007, 78, 1878-1886. [CrossRef]

28. Maeno, M.; Lee, C.; Kim, D.M.; Da Silva, J.; Nagai, S.; Sugawara, S.; Nara, Y.; Kihara, H.; Nagai, M. Function of Platelet-Induced Epithelial Attachment at Titanium Surfaces Inhibits Microbial Colonization. J. Dent. Res. 2017, 96, 633-639. [CrossRef]

29. Persson, L.G.; Lekholm, U.; Leonhardt, A.; Dahlén, G.; Lindhe, J. Bacterial colonization on internal surfaces of Branemark system implant components. Clin. Oral Implant. Res. 1996, 7, 90-95. [CrossRef]

30. Jansen, V.K.; Conrads, G.; Richter, E.J. Microbial leakage and marginal fit of the implant- abutment interface. Int. J. Oral Maxillofac. Implant. 1997, 12, 527-540.

(C) 2020 by the authors. Licensee MDPI, Basel, Switzerland. This article is an open access article distributed under the terms and conditions of the Creative Commons Attribution (CC BY) license (http://creativecommons.org/licenses/by/4.0/). 